\title{
Impact of Turbocharger Non-Adiabatic Operation on Engine Volumetric Efficiency and Turbo Lag
}

\author{
S. Shaaban ${ }^{1}$ and J. Seume ${ }^{2}$ \\ ${ }^{1}$ Mechanical Power Engineering Department, Faculty of Engineering, Helwan University, Cairo 11718, Egypt \\ ${ }^{2}$ Institute of Turbomachinery and Fluid Dynamics, University of Hanover, 30167 Hannover, Germany
}

Correspondence should be addressed to S. Shaaban, shaaban.sameh@yahoo.com

Received 22 October 2011; Revised 18 December 2011; Accepted 23 December 2011

Academic Editor: J-C. Han

Copyright (C) 2012 S. Shaaban and J. Seume. This is an open access article distributed under the Creative Commons Attribution License, which permits unrestricted use, distribution, and reproduction in any medium, provided the original work is properly cited.

\begin{abstract}
Turbocharger performance significantly affects the thermodynamic properties of the working fluid at engine boundaries and hence engine performance. Heat transfer takes place under all circumstances during turbocharger operation. This heat transfer affects the power produced by the turbine, the power consumed by the compressor, and the engine volumetric efficiency. Therefore, nonadiabatic turbocharger performance can restrict the engine charging process and hence engine performance. The present research work investigates the effect of turbocharger non-adiabatic performance on the engine charging process and turbo lag. Two passenger car turbochargers are experimentally and theoretically investigated. The effect of turbine casing insulation is also explored. The present investigation shows that thermal energy is transferred to the compressor under all circumstances. At high rotational speeds, thermal energy is first transferred to the compressor and latter from the compressor to the ambient. Therefore, the compressor appears to be "adiabatic" at high rotational speeds despite the complex heat transfer processes inside the compressor. A tangible effect of turbocharger non-adiabatic performance on the charging process is identified at turbocharger part load operation. The turbine power is the most affected operating parameter, followed by the engine volumetric efficiency. Insulating the turbine is recommended for reducing the turbine size and the turbo lag.
\end{abstract}

\section{Introduction}

Turbocharger performance significantly affects the overall performance of turbocharged engines. Turbocharger operation involves heat transfer under all circumstances. Even if the turbocharger casing is well insulated, heat transfer takes place from the turbine to the lubricating oil [1-3] or from the oil to the compressor at low rotational speeds [4]. Malobabic et al. [5] reported that the turbocharger will operate at a considerably lower speed due to non-adiabatic operation which in turn influences the charging process. Non-adiabatic turbocharger operation can also increase the turbo lag because the time required to accelerate the turbocharger from angular velocity $\omega_{1}$ to $\omega_{2}$ is given by

$$
\Delta t_{\text {acceleration }}=I_{\text {rotor }} \int_{\omega_{1}}^{\omega_{2}} \frac{\omega d \omega}{\dot{W}_{T}-\dot{W}_{C}} .
$$

Turbo lag increases if the actual non-adiabatic turbocharger operation involves a decrease in the turbine power and an increase of the compressor power. Moreover, the turbo lag decreases if the turbine can produce the same power at smaller size (smaller rotor inertia). Rakopoulos et al. [6] reported that turbocharger lag is the most notable off-design feature of diesel engine transient operation that significantly differentiates the torque pattern from the respective steadystate conditions.

It is difficult to measure the non-adiabatic turbine and compressor actual power due to heat transfer between the turbocharger components as well as between the turbocharger and the ambient. The high exhaust gas temperature, the very high rotational speed, and the shaft motion associated with the use of the sliding hydraulic bearing are some factors that increase the difficulty of measuring the compressor torque under non-adiabatic operating conditions. Therefore, non-adiabatic turbocharger operation is investigated using 


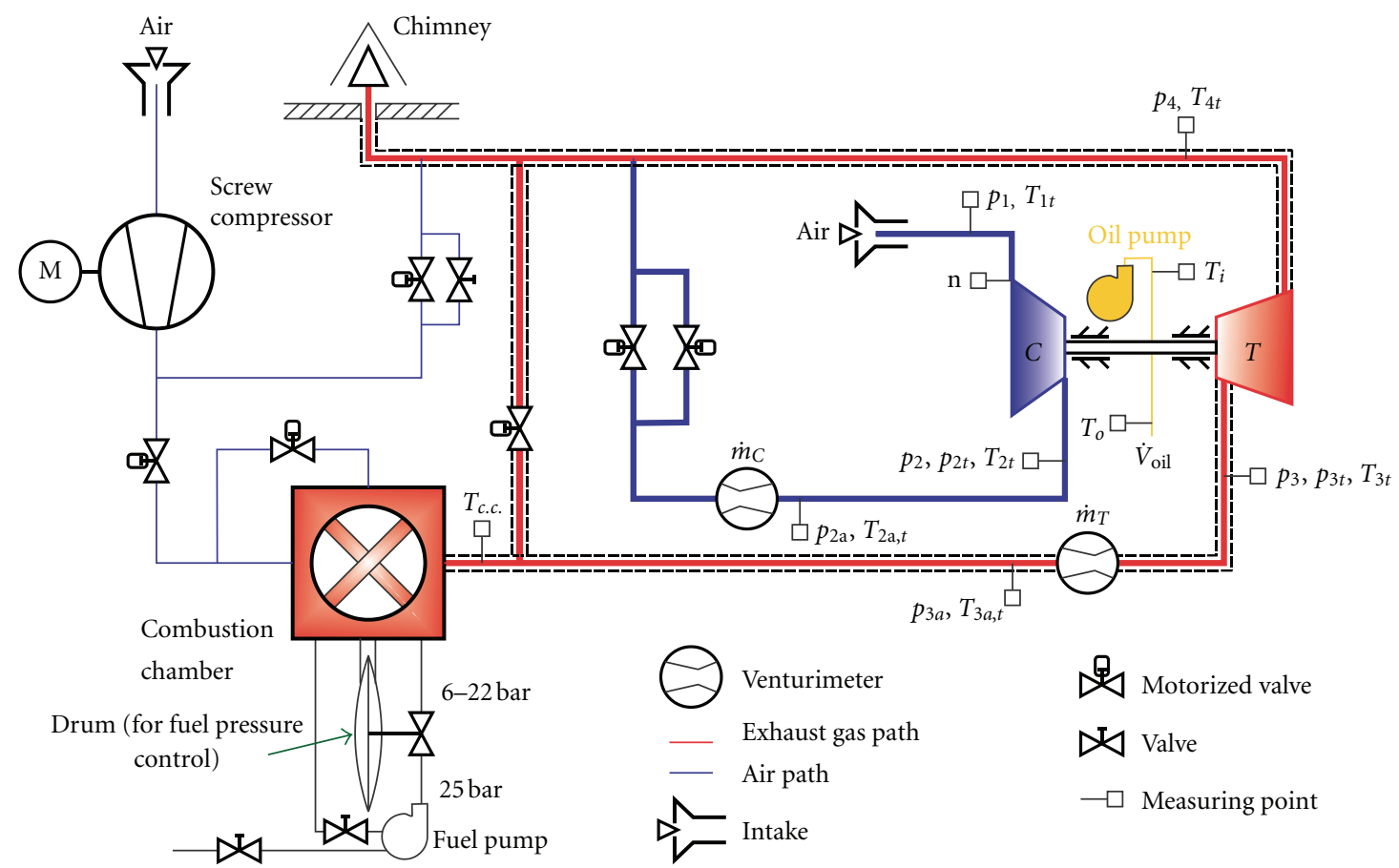

FIGURE 1: Schematic of the small combustion chamber test rig.

either thermodynamic models or CFD simulation. Rautenberg and Kämmer [7] modeled the non-adiabatic compressor performance by decomposing the amount of thermal energy transfer to the compressor into three portions. The first portion takes place before the impeller, the second portion takes place during the compression process in the impeller, and the third portion takes place after the impeller. Hagelstein et al. [8] simplified the model of Rautenberg and Kämmer [7] and decomposed the amount of thermal energy transfer to the compressor into two portions only. The first portion takes place before the compressor impeller, while the second portion takes place after the compressor. They considered the compression process in the impeller to be adiabatic.

Cormerais et al. [9] experimentally and analytically investigate the process of heat transfer inside the turbocharger. Galindo et al. [10] presented an analytical study of a twostage turbocharging with inter- and after cooler. They considered the amount of thermal energy transfer in the turbine side before gas expansion in the turbine. Baar and Lücking [11] presented thermodynamic analysis of the turbocharger non-adiabatic performance by applying energy balance to the turbocharger. Bohn et al. [12-14] performed 3D conjugate calculation for a passenger car turbocharger.

Eriksson et al. [15] modeled a spark ignition turbocharged engine with intercooler. They neglect the effect of heat transfer in the turbocharger. Serrano et al. [16] presented a model of turbocharger radial turbines by assuming that the process undergone by the gas in the turbine is adiabatic but irreversible.

Most of the previous publications concern with the amount of thermal energy exchange between the turbocharger components or even assume the turbocharger to be adiabatic. These investigations are important for engine modeling programs. The present research investigates the probable effect of actual turbocharger non-adiabatic operation on engine volumetric efficiency and turbo lag. It models and estimates the actual turbine and compressor power under real non-adiabatic operating conditions. It also explores the increase in compressed air temperature due to thermal energy transfer to the compressor and estimates its subsequent effect on engine volumetric efficiency.

\section{Test Rig and Measuring Technique}

Experimental investigations are performed on the small combustion chamber test rig of the University of Hanover. Figure 1 shows a schematic of the small combustion chamber test rig. Pressurized air from a screw compressor is supplied to the combustion chamber. Fuel is injected into the combustion chamber and combustion takes place. The exhaust gas from the combustion chamber is supplied to the turbocharger turbine via insulated pipes. The supply temperature of the exhaust gas can be controlled by adjusting the amount of fuel injected in the combustion chamber. Motorized valves are used in order to control the turbine and compressor operating points. It is also possible to switch the combustion chamber off and drive the turbocharger turbine using compressed air from the screw compressor. This type of measurement is called "cold measurement" and it is used to estimate the effect of heat transfer on the turbocharger performance.

Static pressure, total pressure, and total temperature are measured at different locations as shown in Figure 1. Two calibrated venturimeters are used for estimating the turbine 


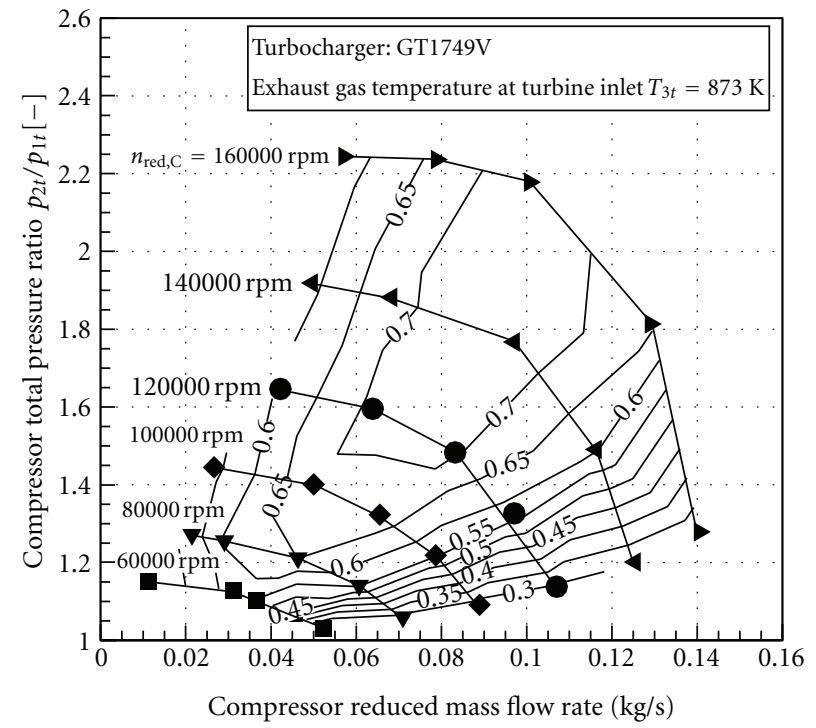

(a)

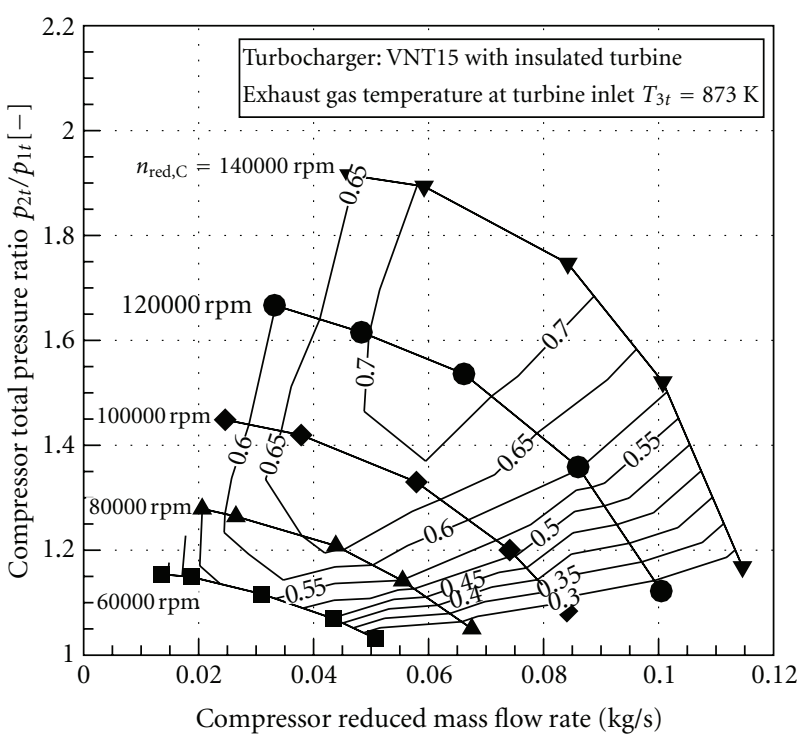

(b)

FIGURE 2: Measured compressor performance maps.

and the compressor mass flow rate. Static pressure measurements are carried out using four static pressure taps of $0.5 \mathrm{~mm}$ diameter at each measuring location. These taps are uniformly distributed around the pipe circumference. Total pressure probes and total temperature probes are used to measure the total pressure and the total temperature, respectively. Total temperature probes have $\mathrm{NiCrNi}$-thermocouples (K-type). Two thermocouples are also used for the measurement of the compressor and turbine casing temperature. Depending on the level of the measured pressure, transducers with measuring ranges of $0-0.350$ bar and $0-2$ bar are used for pressure measurement. Turbocharger rotational speed is measured with an eddy current sensor with a maximum linearity of $\pm 0.2 \%$ of the full scale reading $( \pm 800 \mathrm{rpm})$. Oil volume flow rate is measured with a turbine flow-meter with a linearity of $\pm 0.15 \%- \pm 1 \%$ of the measuring range. A data-acquisition system is used to collect the measured data and send them to a computer. Experimental error analysis is performed and shows that the maximum error in measured compressor efficiency is $\pm 3.5 \%$ and in measured turbine efficiency is $\pm 5.5 \%$. The maximum possible error takes place at the minimum measured rotational speed $(60000 \mathrm{rpm})$.

Experimental results of two turbochargers are presented in the present research work. These turbochargers are the GT1749V and VNT15 by Honeywell Garrett. Both turbochargers have the same overall dimensions $\left(D_{2}=49 \mathrm{~mm}\right.$ and $D_{3}=17 \mathrm{~mm}$ ) but different compressor trim. The GT1749V has a compressor trim of 55 while the trim of the VNT15 equals 45 . Both turbochargers have turbines with variable nozzle geometry. Results of the present research work are all conducted under fully opened turbine nozzle conditions. The GT1749V turbocharger is tested under different exhaust gas temperatures as well as in a "cold measurement". "Cold measurements" are also performed for the VNT15 turbocharger and compared to the turbocharger performance with insulated turbine to investigate the effect of turbine insulation on small turbochargers performance. Figure 2 shows the measured compressor performance maps for both turbochargers.

\section{Actual Compressor Power}

The measured temperature difference across the compressor cannot be used to estimate the actual compressor power even if the turbine casing is insulated [3]. This is because of the thermal energy transfer inside the turbocharger from the hot turbine to the cold lubrication oil and compressor. Methods to separate the aerodynamic compressor work from the amount of thermal energy transferred to the compressor are considered in previous publications (see, e.g., $[2,3]$ ). The present work aims at investigating the effect of thermal energy exchange between turbocharger components on the actual compressor and turbine power and hence the engine charging process.

Figure 3 shows control volumes for the turbine and the compressor. The effect of heat transfer on the compressor power is modeled using the compressor polytropic (smallstage) efficiency. The compressor polytropic efficiency at certain operating point is estimated from "cold measurement" and can therefore be considered as a correct representation of the compressor aerodynamic losses under non-adiabatic operating conditions.

A computer program is established to model the compressor non-adiabatic performance in order to find the actual non-adiabatic compressor power. The program reads the adiabatic (cold measurement) and non-adiabatic (hot measurement) measured compressor maps. The compressor polytropic (small-stage) efficiency is estimated at each compressor operating point from the adiabatic measurement. The non-adiabatic compression process is modeled as shown 

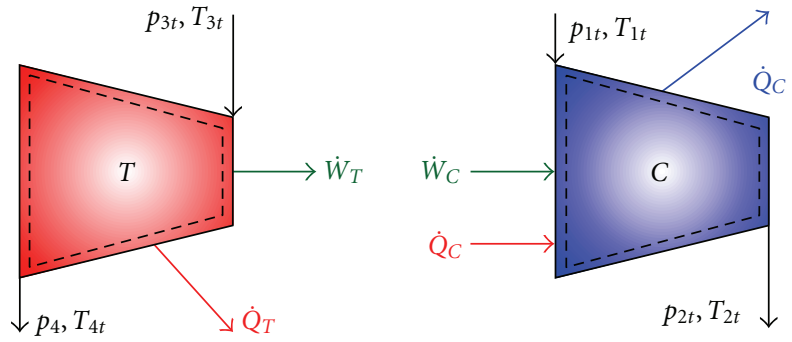

FIGURE 3: Control volumes for the turbine and the compressor.

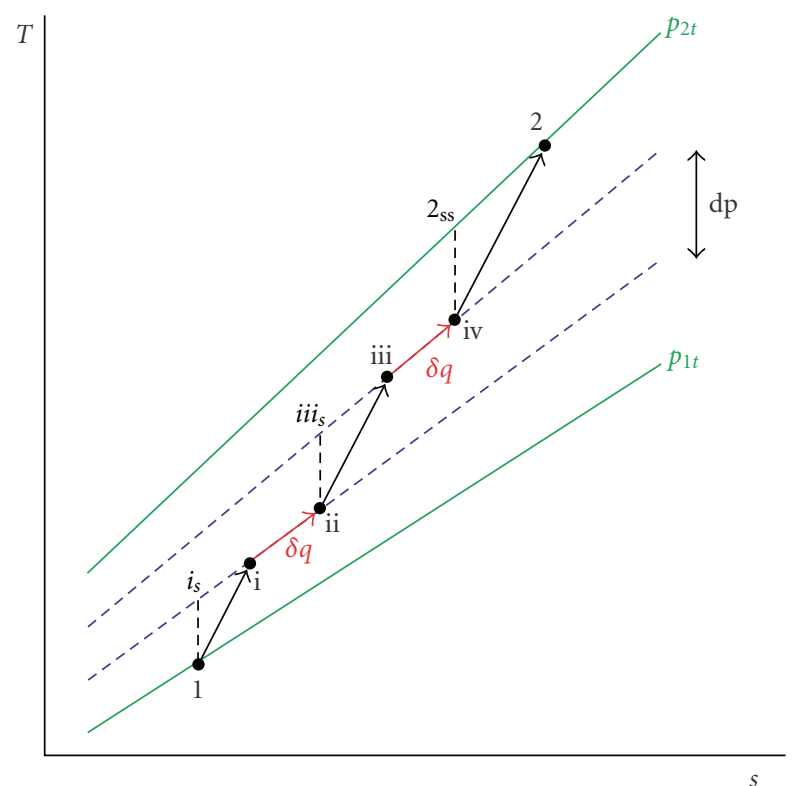

FIGURE 4: Thermodynamic modeling of non-adiabatic compression process.

schematically in Figure 4. At each operating point, the total pressure and total temperature before and after the compressor are known from non-adiabatic measurement (hot measurement). The polytropic efficiency is also known from "cold measurement". The program assumes a value for the amount of thermal energy transferred to the compressor. The total pressure difference across the compressor is divided into a large number of infinitesimal stages in order to enable the use of the polytropic efficiency. The number of stages is changed gradually until no effect of the number of infinitesimal stages on the calculated values is observed. The compression process in each infinitesimal stage is considered to be adiabatic, and the amount of thermal energy transfer " $\delta q$ " is considered to take place between the infinitesimal stages.

The program calculates the whole compression process from the total pressure and total temperature at the compressor inlet to the total pressure at the compressor outlet $p_{2 t}$. The calculated total temperature at the compressor outlet is compared to the measured total temperature. If the difference between the measured and calculated total temperature is greater than a prescribed value $( \pm 0.01 \mathrm{~K})$, a new value for the amount of thermal energy transferred to the compressor is assumed and the calculations are repeated. Calculations are iterated until the measured total temperature at compressor outlet is obtained.

The amount of thermal energy transfer to the compressor that takes place between the infinitesimal stages is considered to be proportional to the surface area and the temperature difference between the compressed air and the casing temperature:

$$
\delta q_{i} \propto d A_{i}\left(T_{C, \text { cas }}-T_{C, i}\right)
$$

With

$$
\begin{aligned}
d A_{i} & =2 \pi r_{i} d r, \\
Q_{C} & =\sum_{i=1}^{N} \delta q_{i},
\end{aligned}
$$

therefore,

$$
\delta q_{i}=\frac{d A_{i}\left(T_{C, \mathrm{cas}}-T_{C, i}\right)}{\sum_{i=1}^{N} d A_{i}\left(T_{C, \mathrm{cas}}-T_{C, i}\right)} Q_{C} .
$$

Equation (2) assumes uniform value of the convective heat transfer coefficient throughout the compressor. To simplify the model and due to the small surface area of the investigated turbochargers, a uniform compressor casing temperature is assumed. A numerical investigation of Bohn et al. [12] confirms this assumption.

Figure 5 shows the estimated amount of thermal energy transferred to the compressor as a fraction of the measured enthalpy difference across the compressor. The amount of thermal energy transfer to the compressor represents a significant fraction of the total enthalpy increase across the compressor at low rotational speed. This fraction decreases with increasing the turbocharger rotational speed due to the increase in the compressor aerodynamic work. An error up to $+35 \%$ in estimating the actual compressor work is expected at $60000 \mathrm{rpm}$ if the measured temperature difference across the compressor is used in estimating the compressor work. This $+35 \%$ error in compressor work increases with decreasing the compressor rotational speed.

Figure 6 shows the estimated percentage increase in compressor work due to heat transfer inside the turbocharger. Results are presented for rotational speed up to $120000 \mathrm{rpm}$ because this is the maximum attainable rotational speed during "cold measurements". Figure 6 shows that the maximum increase in compressor work due to heat transfer is only $2 \%$ at $60000 \mathrm{rpm}$. This percentage is approximately the same for both turbochargers despite the fact that the turbine of the VNT15 turbocharger is insulated. Therefore, the results of Figure 6 assist previous conclusions that most of the heat transfer between the turbine and the compressor takes place in the bearing housing and the lubricating oil removes a considerable part of the heat before it transfers to the compressor $[2,3]$.

Another factor that reduces the effect of heat transfer on the compressor actual power is the relationship between the compressed air temperature and the casing temperature. 


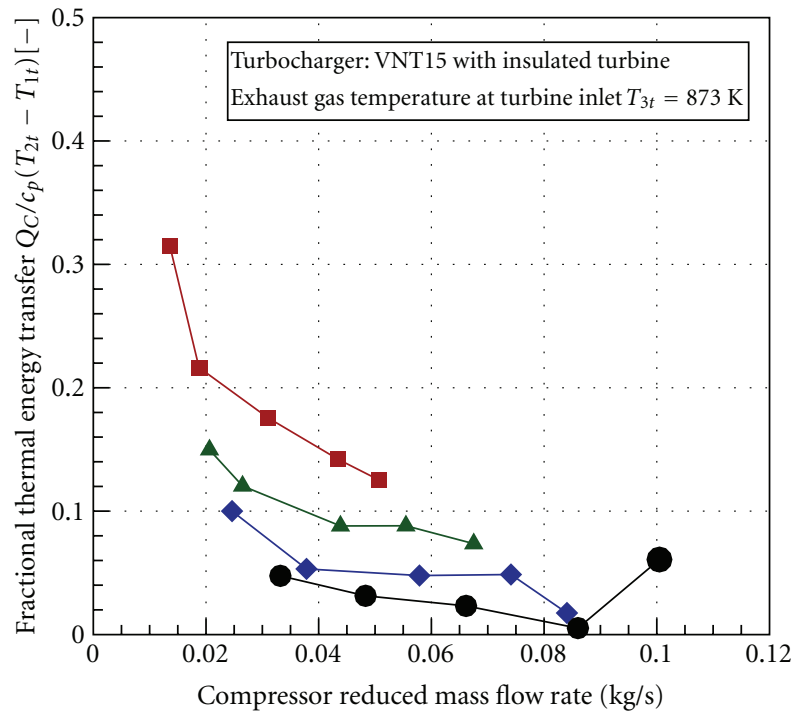

(a)

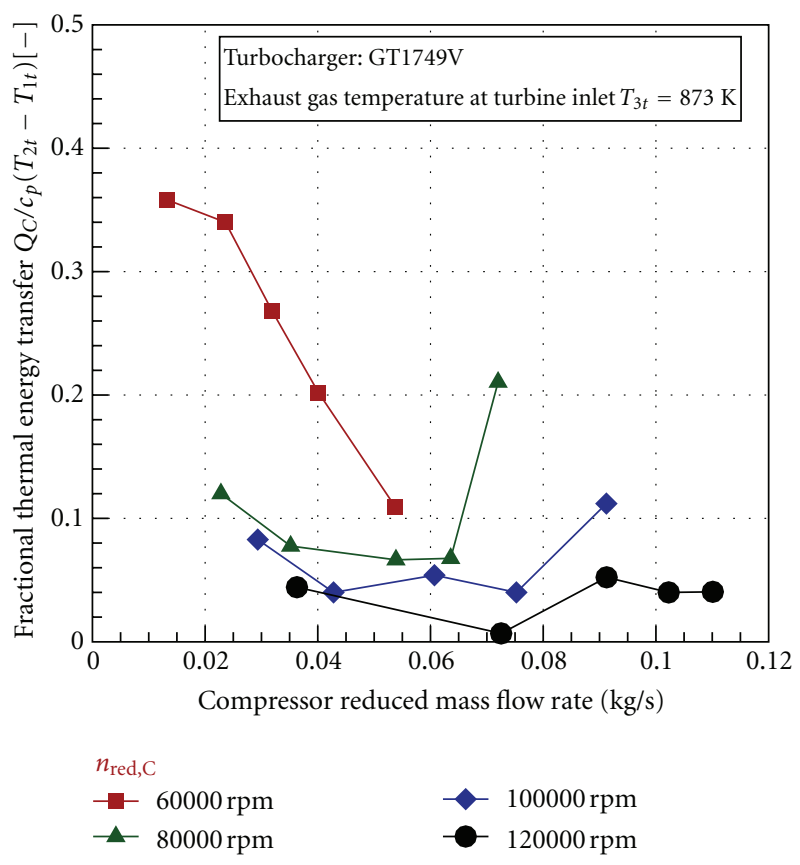

(b)

FIGURE 5: Fractional thermal energy transfer to the compressor.

Figure 7 shows an example for the calculated air temperature during compression at certain operating point of the GT1749V compressor. This point is selected on the surge line because measurement of Pucher et al. [17] shows that engine operating points take place very close to compressor surge line. The measured casing temperature is also presented in Figure 7. Maximum temperature difference between the air and the compressor casing takes place at compressor inlet. The air temperature increases due to compression and thermal energy transferred to the compressor and hence the temperature difference between the air and the compressor casing decreases. At certain point, the

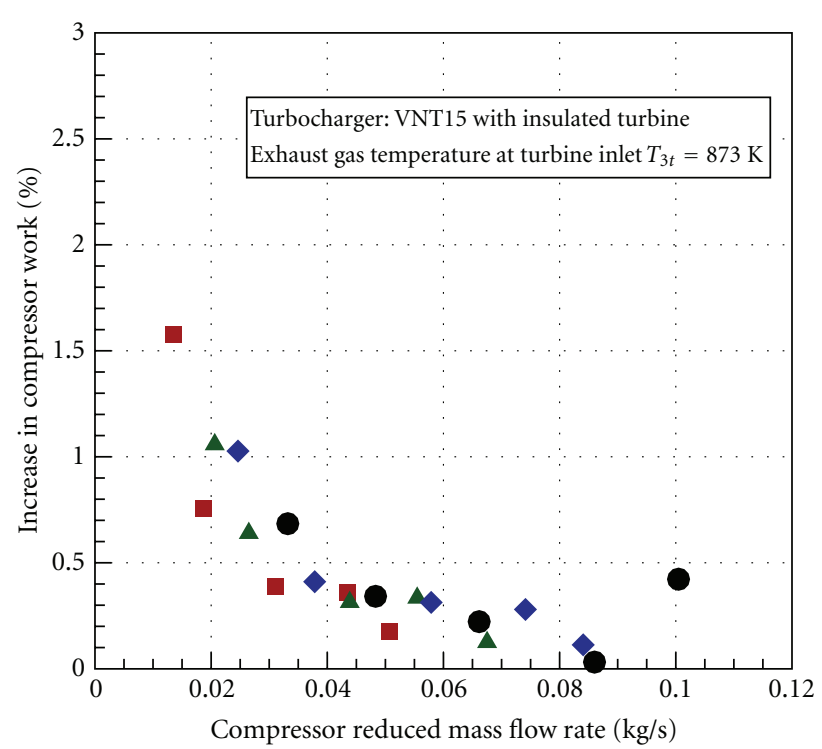

(a)

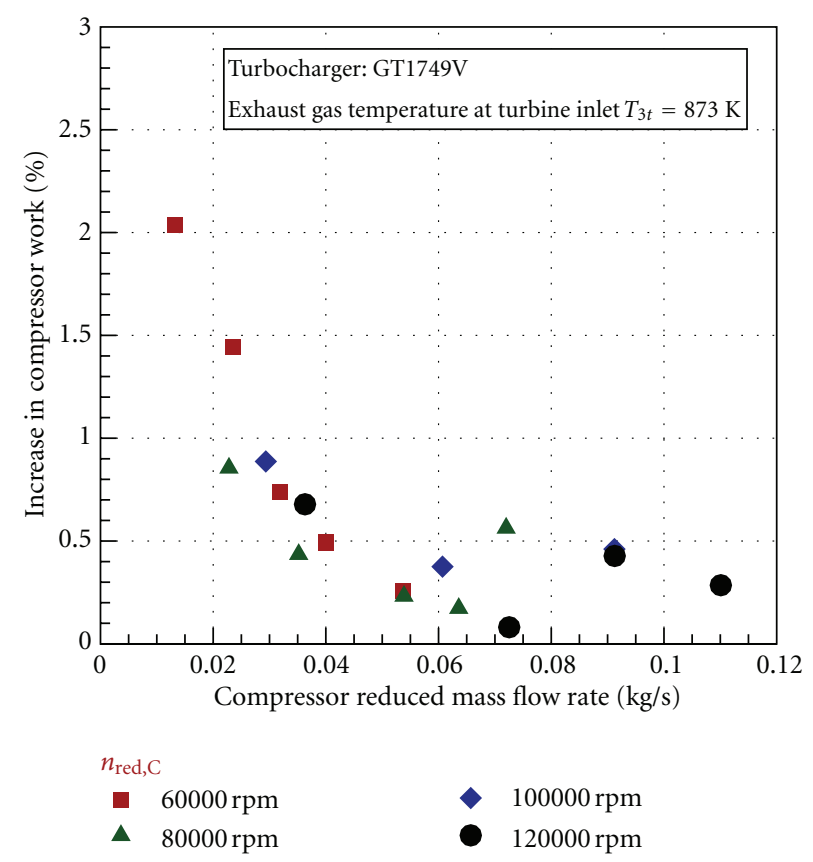

(b)

FIGURE 6: Percentage increase in non-adiabatic compressor work.

compressed air temperature is higher than the casing temperature and heat transfer takes place from the air to the compressor casing.

Figure 8 shows the calculated percentage thermal energy transfer at each stage of the compression process. These values are estimated from the thermodynamic model described previously. The percentage thermal energy transfer to the compressor increases at the beginning of the compression process due to the increase in the area of heat transfer $\left(A_{i}=\right.$ $\left.2 \pi r_{i} d r\right)$. The amount of heat transfer to the compressor decreases latter because the decrease in the temperature difference between the air and the casing (Figure 7) overcomes 


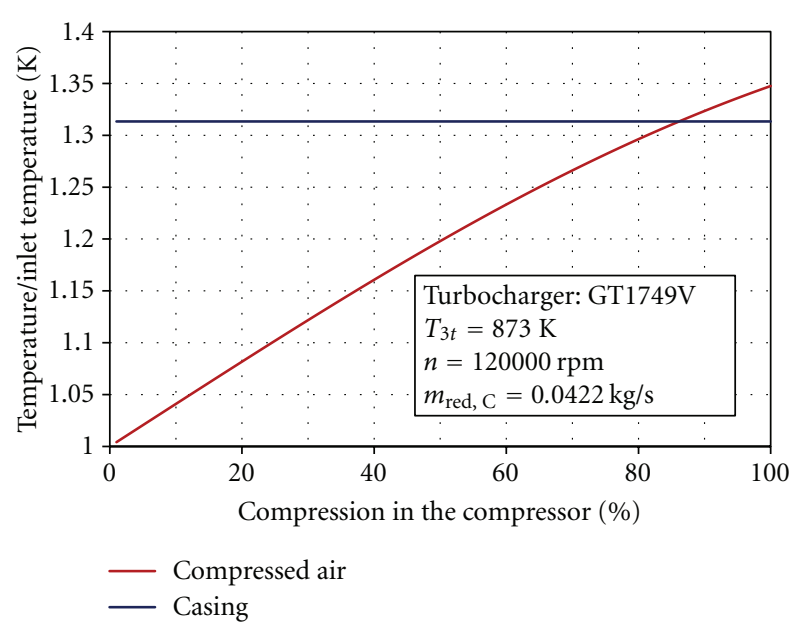

FIGURE 7: Temperature variation during compression.

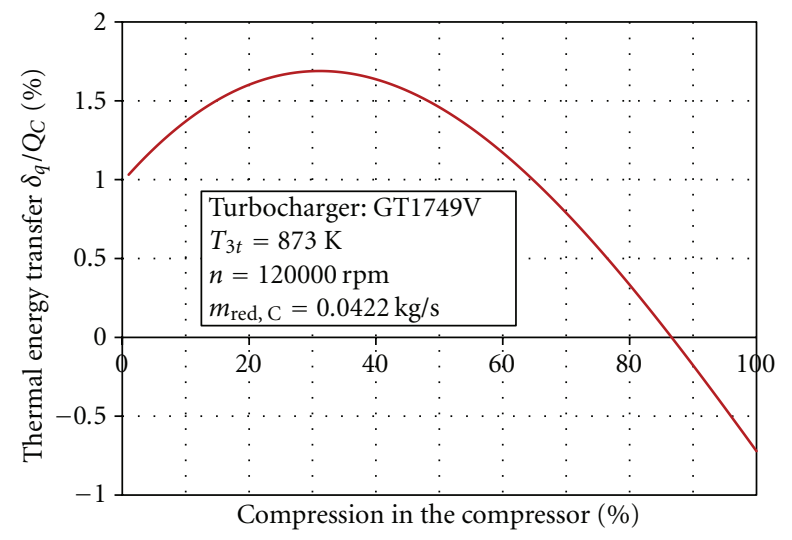

FIGURE 8: Fraction of thermal energy transfer during compression.

the increase in heat transfer area. The air temperature increases further and becomes greater than the casing temperature for this operating point. Consequently, heat transfer takes place from the compressor to the ambient as shown in Figure 8.

According to these results, two modes of thermal energy transfer to the compressor can be identified as shown in Figure 9. At low rotational speeds, thermal energy transfers to the compressor and causes a significant increase in the compressor outlet temperature $T_{2 t}$ and $2 \%$ increase in the real compressor power. Thermal energy also transfers to the compressor at moderate and high rotational speeds. However, the rapid and high increase in air temperature causes thermal energy transfer from the compressor to the surrounding near the end of compression process. Therefore, thermal energy transfers to the compressor at the beginning then from the compressor to the ambient near the end of the compression process. The net result is a small effect of the thermal energy transfer to the compressor on the measured compressor performance at moderate rotational speed (120000 rpm in the present case). The thermal energy transfer to the compressor decreases further at high compressor rotational speed while the thermal energy transfer from the

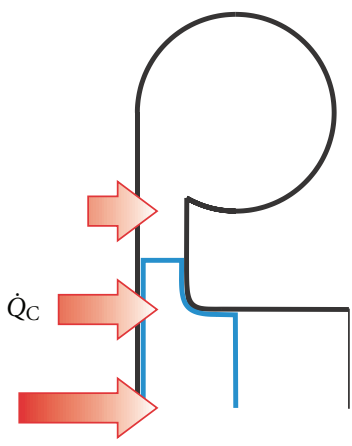

Low rotational speed

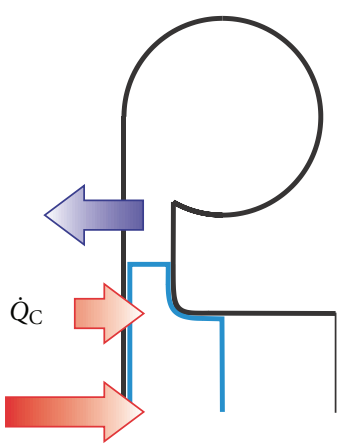

High rotational speed
FIGURE 9: Modes of thermal energy transfer to the compressor.

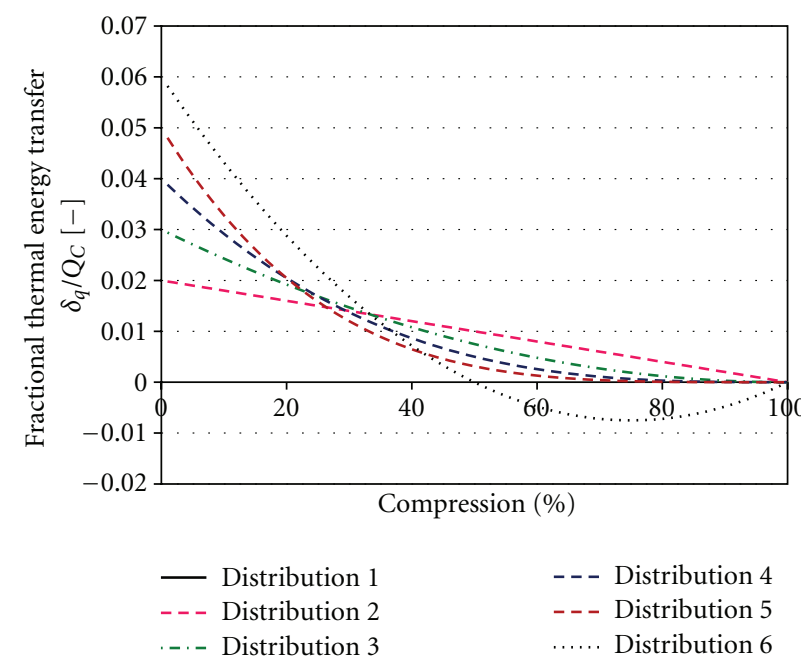

FIGURE 10: Hypothetical distribution of thermal energy transfer inside compressor.

compressor to the surrounding substantially increases. They almost cancel each other, and the net result is an apparent adiabatic compression process with minimum effect on both the total temperature at compressor outlet and actual compressor power. Although previous conclusions suggested that the compressor can be assumed adiabatic at high rotational speeds $[2,3]$, present model shows that the compressor is not adiabatic under all circumstances. However, the effect of heat transfer to the compressor is minor at high rotational speeds due to the thermal energy transfer mechanisms described in Figure 9. It is also concluded that thermal energy transfer to the compressor has a minor effect on compressor power and turbo lag as long as the lubricating oil removes most of the thermal energy transfer from the turbine to the bearing housing. Although the aforementioned compressor heat distribution seems realistic, it has not been verified by direct experimental results.

The previous heat transfer model (2) assumes uniform convective heat transfer coefficient throughout the compressor. To validate this model and check whether the assumed thermal energy distribution (2) significantly affects the estimated compressor performance or not, six different 


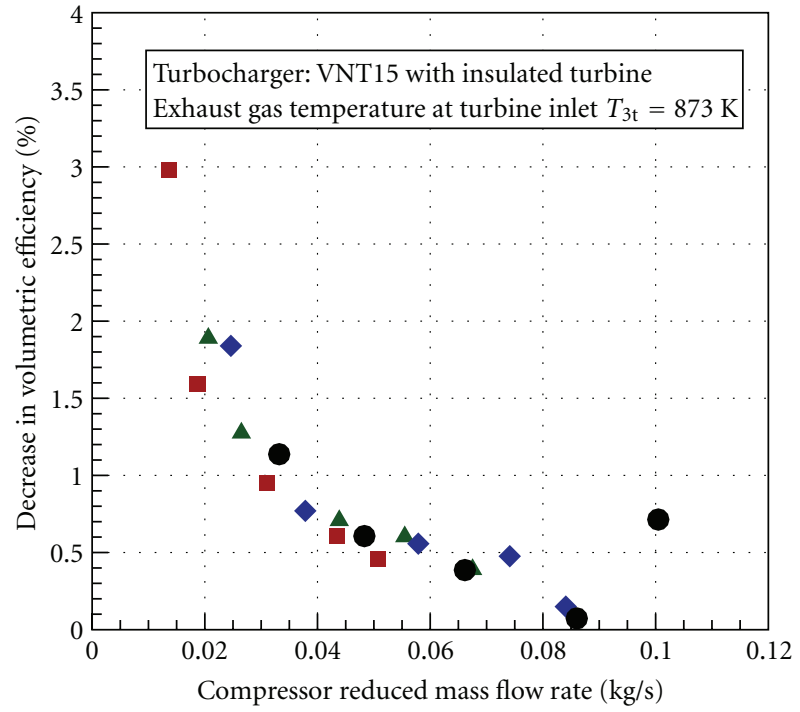

(a)

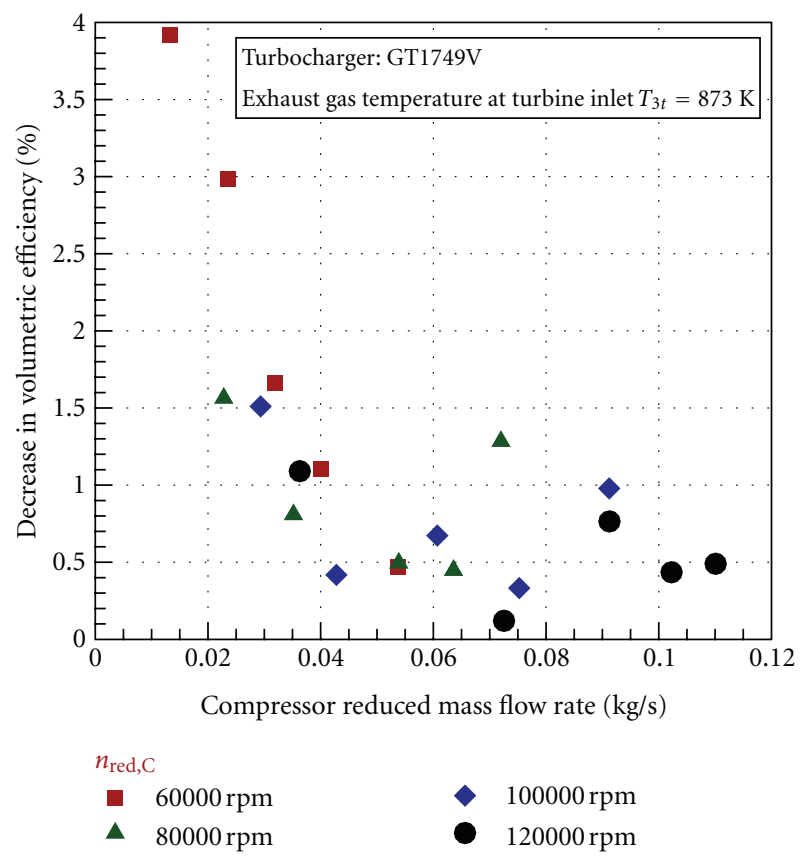

(b)

FIgURE 11: Decrease in engine volumetric efficiency.

hypothetical distributions of thermal energy transfer inside the compressor are assumed as shown in Figure 10.

The first distribution "distribution 1" has uniformly distributed thermal energy transfer to the compressor. Thermal energy transfer to the compressor at the beginning of compression is increased gradually from "distribution 2" to "distribution 6" where thermal energy transfer from the compressor takes place at the end of the process in "distribution 6". Table 1 shows the maximum estimated increase of non-adiabatic work for the GT1749V compressor. Increasing the amount of thermal energy transfer to the compressor in early stages of compression (in the impeller) results in more increase in the compressor actual power. The maximum increase in compressor power stills however less than $3 \%$ in all distributions. This small percentage is mainly due to the oil which acts like a thermal barrier that significantly reduces heat transfer to the compressor.

\section{Engine Volumetric Efficiency}

Another important effect of thermal energy transfer to the compressor on engine performance is its effect on engine volumetric efficiency. Figure 5 shows that the enthalpy difference across the compressor increases by $35 \%$ close to the compressor surge point at $60000 \mathrm{rpm}$. Since engine operating points are located close to the compressor surge line, the increase in compressed air temperature due to thermal energy transfer to the compressor can affect the engine volumetric efficiency. Figure 11 shows the percentage decrease in engine volumetric efficiency due to thermal energy transfer to the compressor. This percentage decrease in engine volumetric efficiency is estimated from

Percentage change in engine volumetric efficiency

$$
=\frac{\rho_{2, \text { non-adiabatic }}-\rho_{2, \text { adiabatic }}}{\rho_{2, \text { adiabatic }}} \text {. }
$$

Compressed air density is estimated from the ideal gas equation of state:

$$
\begin{gathered}
\rho_{2, \text { non-adiabatic }}=\frac{p_{2}}{R_{\text {air }} T_{2}}, \\
\rho_{2 \text {, adiabatic }}=\frac{p_{2}}{R_{\text {air }} T_{2, \text { adiabatic }}},
\end{gathered}
$$

where $T_{2}$ is the measured air temperature at compressor exit, and $T_{2}$, adiabatic is the air temperature at compressor outlet if compression is adiabatic:

$$
T_{2, \text { adiabatic }}=T_{2}-\frac{Q_{C}}{c_{p, \text { air }}} .
$$

Results for both turbochargers show 3-4\% decrease in engine volumetric efficiency at $60000 \mathrm{rpm}$. This percentage decrease in volumetric efficiency increases further with decreasing compressor rotational speed. Since the turbocharger rotational speed at engine start can be as low as $30000 \mathrm{rpm}$, it is concluded that thermal energy transfer to the compressor has tangible effect on engine volumetric efficiency during engine starting, no-load and part-load engine operation.

\section{Actual Turbine Power}

Heat transfers from the turbine to the surrounding, bearing housing, lubricating oil, and compressor. The turbine dissipates considerable part of its energy in the form of heat. Therefore, the effect of heat transfer on turbine and hence engine performance is investigated. "Cold measurements" are considered as the adiabatic turbine performance while "hot measurements" represent the non-adiabatic performance. Cold and hot measurements are compared at the same rotational speed and guide vanes position in order 


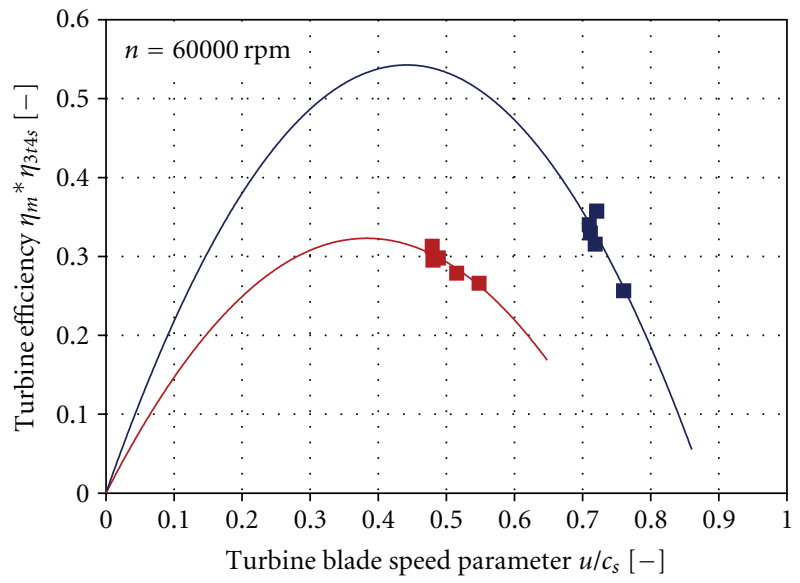

(a)

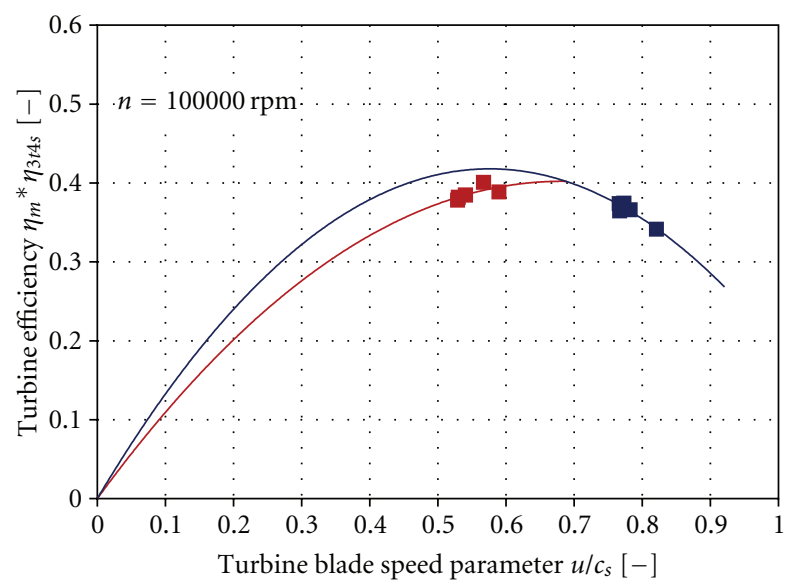

Exhaust gas temperature at turbine inlet:

- $973 \mathrm{~K}$

- $305 \mathrm{~K}$ (adiabatic turbine)

(c)

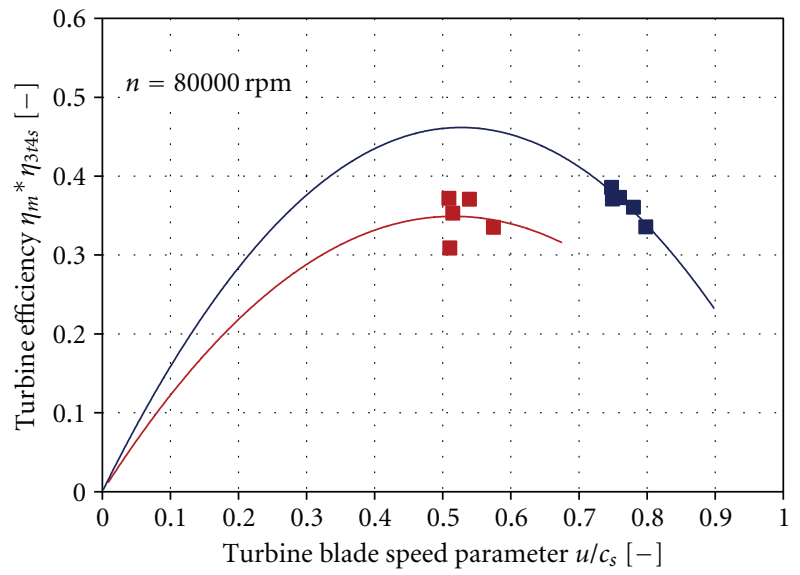

(b)

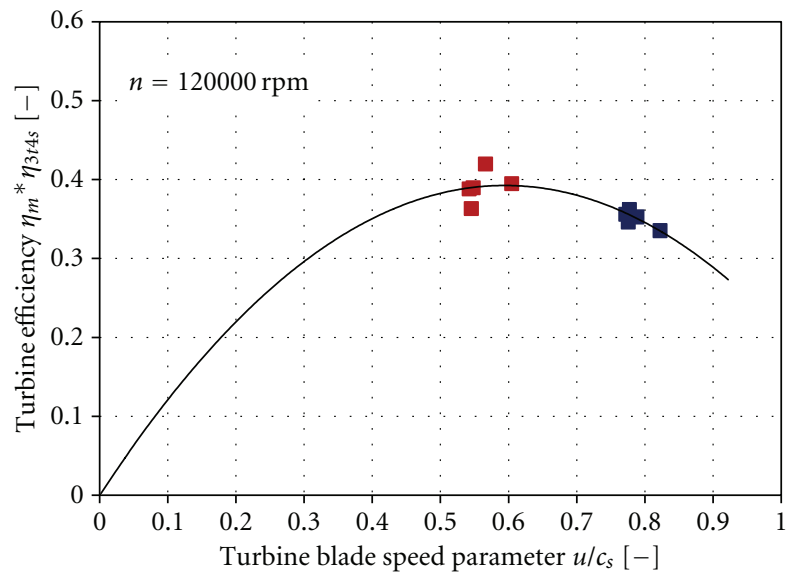

Exhaust gas temperature at turbine inlet:

- $973 \mathrm{~K}$

- $305 \mathrm{~K}$ (adiabatic turbine)

(d)

FIgURE 12: Non-adiabatic versus adiabatic turbine efficiency of the GT1749V turbine.

TABLE 1: Maximum increase of the GT1749V non-adiabatic compressor work.

\begin{tabular}{lcccccc}
\hline Equation (2) & Distribution 1 & Distribution 2 & Distribution 3 & Distribution 4 & Distribution 5 & Distribution 6 \\
\hline $2.04 \%$ & $1.45 \%$ & $1.84 \%$ & $2.14 \%$ & $2.19 \%$ & $2.35 \%$ & $2.73 \%$ \\
\hline
\end{tabular}

to keep the effect of outward centrifugal force and guide vanes position on the measured efficiency constant. Figure 12 shows the measured non-adiabatic and adiabatic turbine efficiencies of the GT1749V turbine as a function of the turbine blade speed parameter $u / c_{s}$ :

$$
\frac{u}{c_{s}}=\frac{\pi D_{3} n / 60}{\sqrt{2 c_{p, \operatorname{exh}}\left(T_{3 t}-T_{4}\right)}}
$$

The turbine total to static efficiency presented in Figure 12 is the actual turbine efficiency:

$$
\eta_{m} \eta_{3 t 4 s}=\frac{\dot{m}_{C} w_{C}}{\dot{m}_{T} c_{p, \text { exh }} T_{3 t}\left[1-\left(p_{3 t} / p_{4}\right)^{-\left(\kappa_{\mathrm{exh}}-1\right) / \kappa_{\mathrm{exh}}}\right]}
$$

where $w_{C}$ is the actual compressor work.

Thermal energy transfer from the turbine significantly affects the turbine efficiency and power produced at low rotational speeds. At $60000 \mathrm{rpm}$, the non-adiabatic turbine power is about $55 \%$ of the power produced by an adiabatic turbine that operates at the same total-to-static enthalpy difference, rotational speed, and guide vanes position. This means that thermal energy transfer from the turbine significantly reduces turbine power and influences the turbo lag at no-load and part-load engine operation as well as during engine start up. The turbine power increases with increasing the turbine rotational speed and therefore the effect of heat transfer from the turbine on turbine power is reduced. No clear effect of the thermal energy transfer from the turbine 


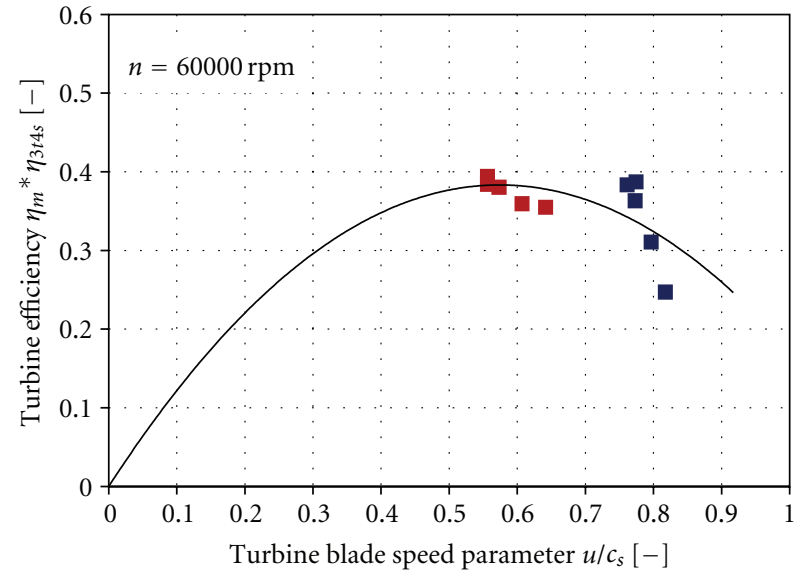

(a)

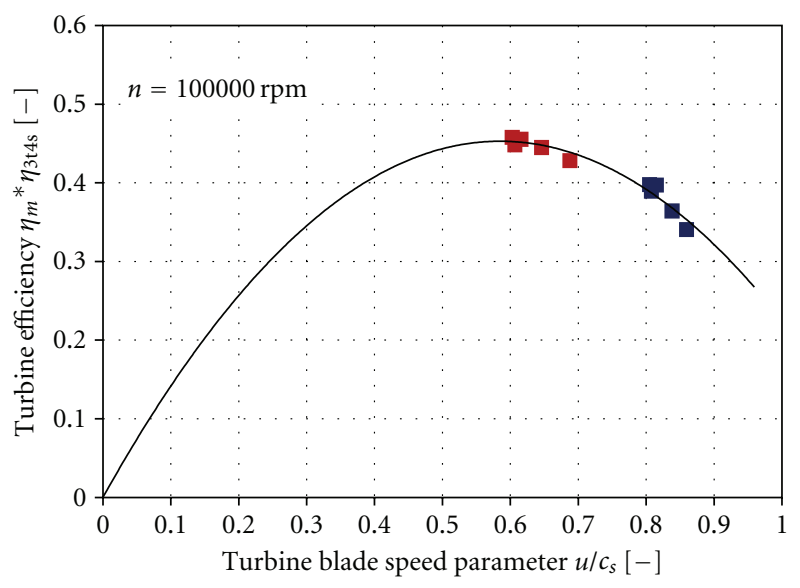

Exhaust gas temperature at turbine inlet:

a $873 \mathrm{~K}$ (insulated turbine)

- $302 \mathrm{~K}$ (adiabatic turbine)

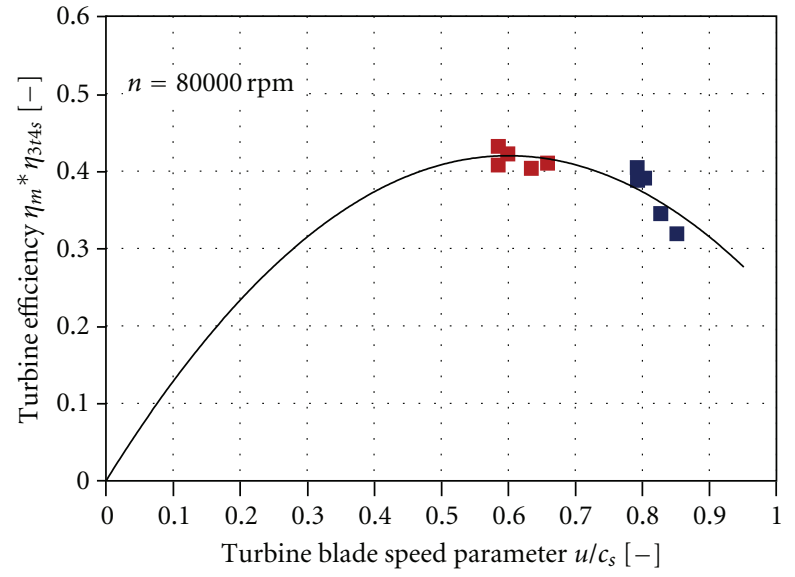

(b)

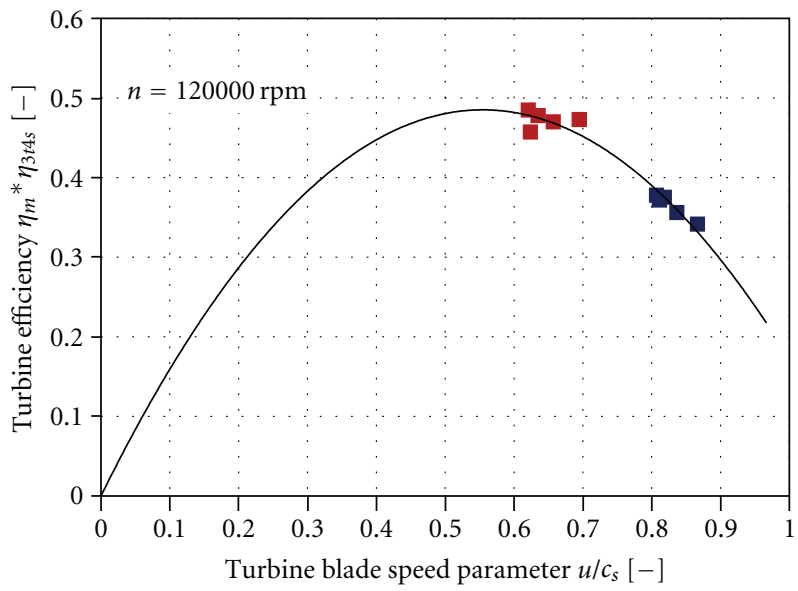

Exhaust gas temperature at turbine inlet:

- $873 \mathrm{~K}$ (insulated turbine)

- $302 \mathrm{~K}$ (adiabatic turbine)

(d)

FIGURE 13: Non-adiabatic versus adiabatic turbine efficiency of the VNT15 turbine.

on the produced turbine power is identified at $120000 \mathrm{rpm}$ due to the high turbine aerodynamic work at high rotational speeds.

The VNT15 turbocharger is also experimentally tested to further investigate the effect of thermal energy transfer on the produced turbine power. This time, the turbine casing is insulated to investigate the effect of placing heat shields around the turbine during real engine operation. It should be noted that heat transfers from the turbine to the lubricating oil and to the compressor even with insulating material placed around the turbine. Previous measurements (see Shaaban, 2004 [2]) show that thermal energy transfer to the oil is about $30 \%$ of the total thermal energy transfer from the turbine.

Figure 13 shows that the insulation placed around the turbine has clearly improved the turbine non-adiabatic efficiency. At fixed turbine guide vanes position, both the turbine adiabatic and non-adiabatic efficiency can be presented by the same function of the blade speed parameter. Therefore, no clear effect of the thermal energy transfer from the turbine on turbine efficiency and power can be identified. These results show that placing a heat shield around the turbine reduces the amount of thermal energy transfer from the turbine and increase the turbine power at part load. Therefore, insulated turbines can deliver the same power at smaller size which can reduce turbo lag.

The experimental results show that the temperature at turbine exit increases with insulating the turbine. However, the maximum increase in the total temperature at turbine exit is less than $19^{\circ} \mathrm{C}$ at $60000 \mathrm{rpm}$. Although the maximum increase of the exhaust temperature at turbine exit is less than $2.4 \%$, further investigations of potential effects of turbine insulation on the performance and lifetime of turbocharger components are recommended for future work.

\section{Conclusions}

The present research investigates the effect of non-adiabatic turbocharger performance on engine volumetric efficiency 
and turbo lag. Two turbochargers are experimentally investigated by comparing adiabatic measurements (cold measurements) with non-adiabatic measurements (hot measurements).

Actual compressor performance under non-adiabatic operating conditions is modeled with the help of the polytropic compressor efficiency. The polytropic compressor efficiency is obtained from cold measurement where the compressor is assumed to be adiabatic. A computer program is established to estimate the actual compressor power and the amount of thermal energy transfer to the compressed air under non-adiabatic operating conditions.

The present research shows that thermal energy transfers to the compressor under all circumstances. However, there are two modes of thermal energy transfer to the compressor. The first mode takes place at low rotational speeds where the compressor receives thermal energy from the turbine and the compressed air temperature is small, so thermal energy transfer from the compressor to the ambient is negligible.

The second mode starts at moderate rotational speeds (120000 rpm in the present case) where thermal energy transfers to the compressor at the beginning of the compression process and then from the compressor to the ambient near the end of the compression process. The net effect is a small net amount of thermal energy transfer to the compressed air with tiny effect on the compressor power. At higher rotational speeds ( $\geq 140000 \mathrm{rpm}$ in the present case), the net thermal energy transfer to/from the compressor could be very small and therefore the compressor appears to be adiabatic from the isentropic efficiency point of view despite its complex heat transfer process.

Although the amount of thermal energy transfer to the compressor can be higher than $35 \%$ of its overall enthalpy difference, its effect on compressor actual work is small. The estimated increase in compressor power due to nonadiabatic operation is less than 3\% for all investigated cases at $60000 \mathrm{rpm}$. Therefore, non-adiabatic compressor operation has small effect on turbo lag during engine startup and partload engine operation.

Thermal energy transfer to the compressor also affects engine volumetric efficiency at no-load and part-load engine operation as well as during engine start. Engine volumetric efficiency is found to decrease by $4 \%$ at $60000 \mathrm{rpm}$. This percentage decrease in the volumetric efficiency increases by decreasing the turbocharger rotational speed.

The most significant effect of turbocharger non-adiabatic performance on turbo lag is identified at the turbine. Experimental data show $55 \%$ decrease of the turbine actual power at $60000 \mathrm{rpm}$ due to thermal energy transfer from the turbine. The effect of thermal energy transfer from the turbine on turbine power decreases with increasing the turbine rotational speed at constant exhaust gas temperature at the turbine inlet. This decrease is due to the rapid increase in the turbine power with increasing the rotational speed relative to the amount of thermal energy transfer from the turbine.

Experimental data also show that insulating the turbine significantly improves the non-adiabatic turbine performance. An insulated turbine can be manufactured in smaller size for the same engine and thus improves turbo lag. It is therefore recommended to insulate the turbine and provide compressor cooling in order to improve the turbocharger non-adiabatic performance and hence the engine performance.

Experimental data also show that insulting the turbine results in $2.4 \%$ increase of the exhaust gas temperature at turbine exit. Therefore, investigation of the effect of turbine insulation on the performance and lifetime of other turbocharger components is recommended for future work.

\section{Nomenclatures}

$\begin{array}{ll}A: & \text { Area } \\ c_{p}: & \text { Specific heat at constant pressure } \\ D: & \text { Diameter } \\ \eta: & \text { Efficiency } \\ I: & \text { Moment of inertia } \\ \dot{m}: & \text { Mass flow rate } \\ n: & \text { Rotational speed } \\ p: & \text { Pressure } \\ Q: & \text { Amount of thermal energy transfer } \\ R: & \text { Gas constant } \\ r: & \text { Radius } \\ \rho: & \text { Density } \\ s: & \text { Entropy } \\ T: & \text { Total temperature } \\ u / c_{s}: & \text { Turbine blade speed parameter } \\ w: & \text { Work } \\ \omega: & \text { angular velocity } \\ \dot{W}: & \text { Power. }\end{array}$

\section{Subscript}

\begin{tabular}{ll} 
1: & Compressor inlet \\
2: & Compressor outlet \\
3: & Turbine inlet \\
4: & Turbine outlet \\
Air: & Air \\
C: & Compressor \\
Cas: & Casing \\
Exh: & Exhaust gas \\
m: & Mechanical \\
T: & Turbine \\
\hline
\end{tabular}

Rotor: Rotor.

\section{References}

[1] K. S. Chapman, R. Nguru, and J. Shultz, "Simplified methodology to correct turbocharger field measurements for heat transfer and other effects," Final Report for Gas Research Institute GRI-02/0156, 2002.

[2] S. Shaaban, Experimental investigation and extended simulation of turbocharger non-adiabatic performance, $\mathrm{Ph} . \mathrm{D}$. dissertation, University of Hanover, Hannover, Germany, 2004.

[3] S. Shaaban and J. R. Seume, "Analysis of turbocharger nonadiabatic performance," in Proceedings of the 8th International Conference on Turbochargers and Turbocharging, C647/027, pp. 119-130, London, UK, May 2006. 
[4] H. Pucher and J. Nickel, "Vermessung erweiterter Kennfeldbereiche von Fahrzeugmotoren-Turboladern," in Proceedings of the 8th Aufladetechnische Konferenz, pp. 321-339, Dresden, Germany, October 2002.

[5] M. Malobabic, A. Mobarak, and M. Rautenberg, "Influence of heat transfer between turbine and compressor on the performance of small turbochargers," in Proceedings of the International Gas Turbine Congress (GTSJ '83), pp. 566-574, Tokyo, Japan, 1983.

[6] C. D. Rakopoulos, A. M. Dimaratos, E. G. Giakoumis, and D. C. Rakopoulos, "Evaluation of the effect of engine, load and turbocharger parameters on transient emissions of diesel engine," Energy Conversion and Management, vol. 50, no. 9, pp. 2381-2393, 2009.

[7] M. Rautenberg and N. Kämmer, "On the thermodynamics of non-adiabatic compression and expansion processes in turbomachines," in Proceedings of the 5th International Conference for Mechanical Power Engineering, Cairo, Egypt, October 1984.

[8] D. Hagelstein, B. Beyer, J. Seume, H. Haseman, and M. Rautenberg, "Heuristical view on the non-adiabatic coupling system of combustion engine and turbocharger," in Proceedings of the IMechE International Conference on Turbocharging and Turbochargers, London, UK, 2002.

[9] M. Cormerais, P. Chesse, and J. F. Hetet, "Turbocharger heat transfer modeling under steady and transient conditions," International Journal of Thermodynamics, vol. 12, no. 4, pp. 193-202, 2009.

[10] J. Galindo, J. R. Serrano, H. Climent, and O. Varnier, "Impact of two-stage turbocharging architectures on pumping losses of automotive engines based on an analytical model," Energy Conversion and Management, vol. 51, no. 10, pp. 1958-1969, 2010.

[11] R. Baar and M. Lücking, "Anforderung an zukünftige PKWAufladesysteme auf Basis der Energiebilanz eines Turboladers," in Proceedings of the 8th Aufladetechnische Konferenz, pp. 243-264, Dresden, Germany, October 2002.

[12] D. Bohn, T. Heuer, N. Moritz, and M. Wolff, "Modellierung des Wärmeflusses im und am System Turbolader," Final Report for Forschungsvereinigung Verbrennungskraftmaschinen FVV FVV Project number 755, Heft 760, 2003.

[13] D. Bohn, T. Heuer, and K. Kusterer, "Conjugate flow and heat transfer investigation of a turbocharger: part I: numerical results," in Proceedings of the ASME Turbo Expo, Paper no. GT2003-38445, pp. 16-19, Atlanta, Ga, USA, June 2003.

[14] D. Bohn, T. Heuer, and K. Kusterer, "Conjugate flow and heat transfer investigation of a turbocharger: part II: experimental results," in Proceedings of the ASME Turbo Expo, Paper no. GT2003-38449, Atlanta, Ga, USA, June 2003.

[15] L. Eriksson, L. Nielsen, J. Brugård, J. Bergström, F. Pettersson, and P. Andersson, "Modeling of a turbocharged SI engine," Annual Reviews in Control, vol. 26, pp. 129-137, 2002.

[16] J. R. Serrano, F. J. Arnau, V. Dolz, A. Tiseira, and C. Cervelló, "A model of turbocharger radial turbines appropriate to be used in zero- and one-dimensional gas dynamics codes for internal combustion engines modelling," Energy Conversion and Management, vol. 49, no. 12, pp. 3729-3745, 2008.

[17] H. Pucher, R. Berndt, P. Grigoriadis et al., "Erweiterte darstellung und extrapolation von turbolader-Kennfeldern als randbedingung der motorprozesssimulation," FVV Informationstagung Motoren Heft R513, Frankfurt, Germany, 2001. 

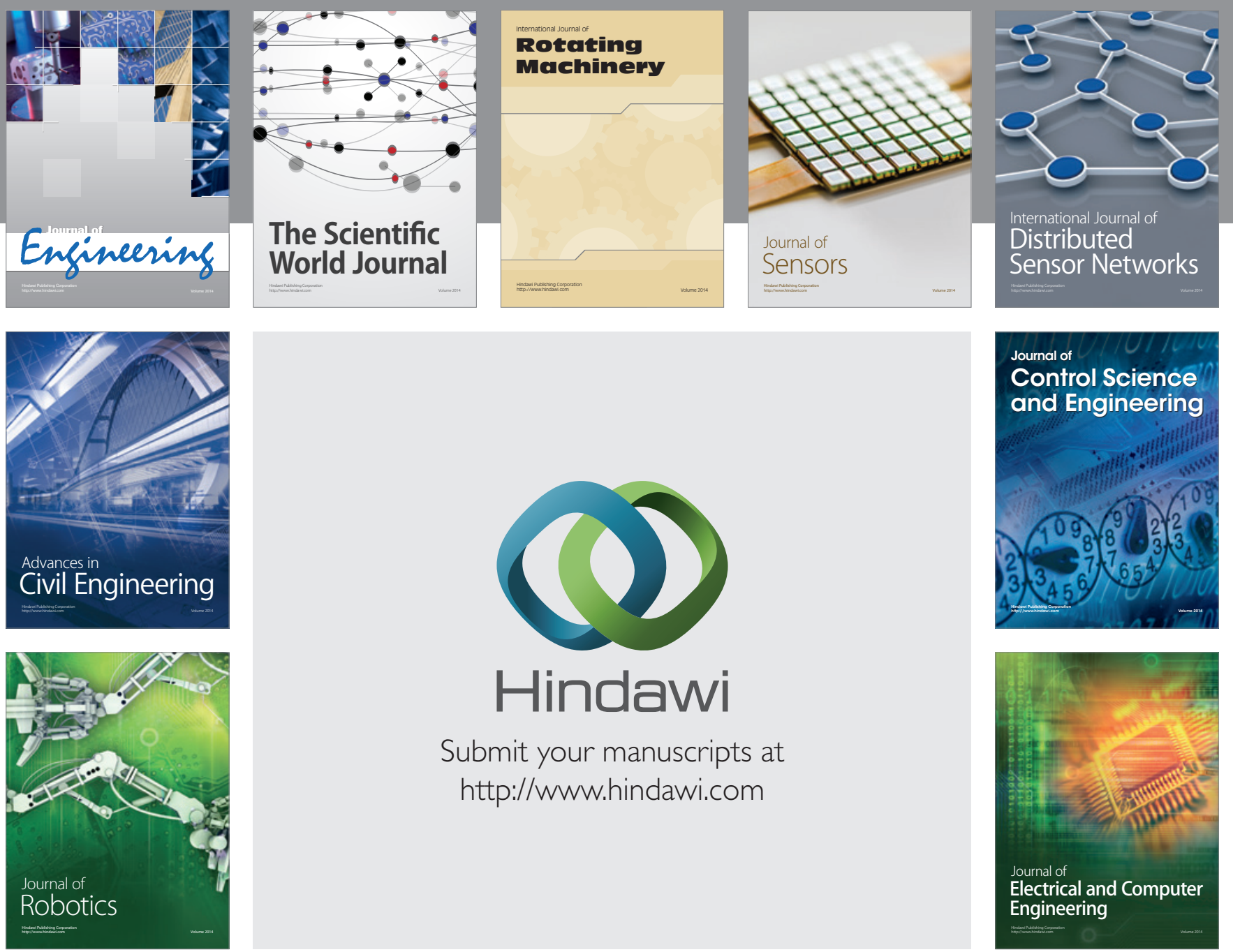

Submit your manuscripts at

http://www.hindawi.com
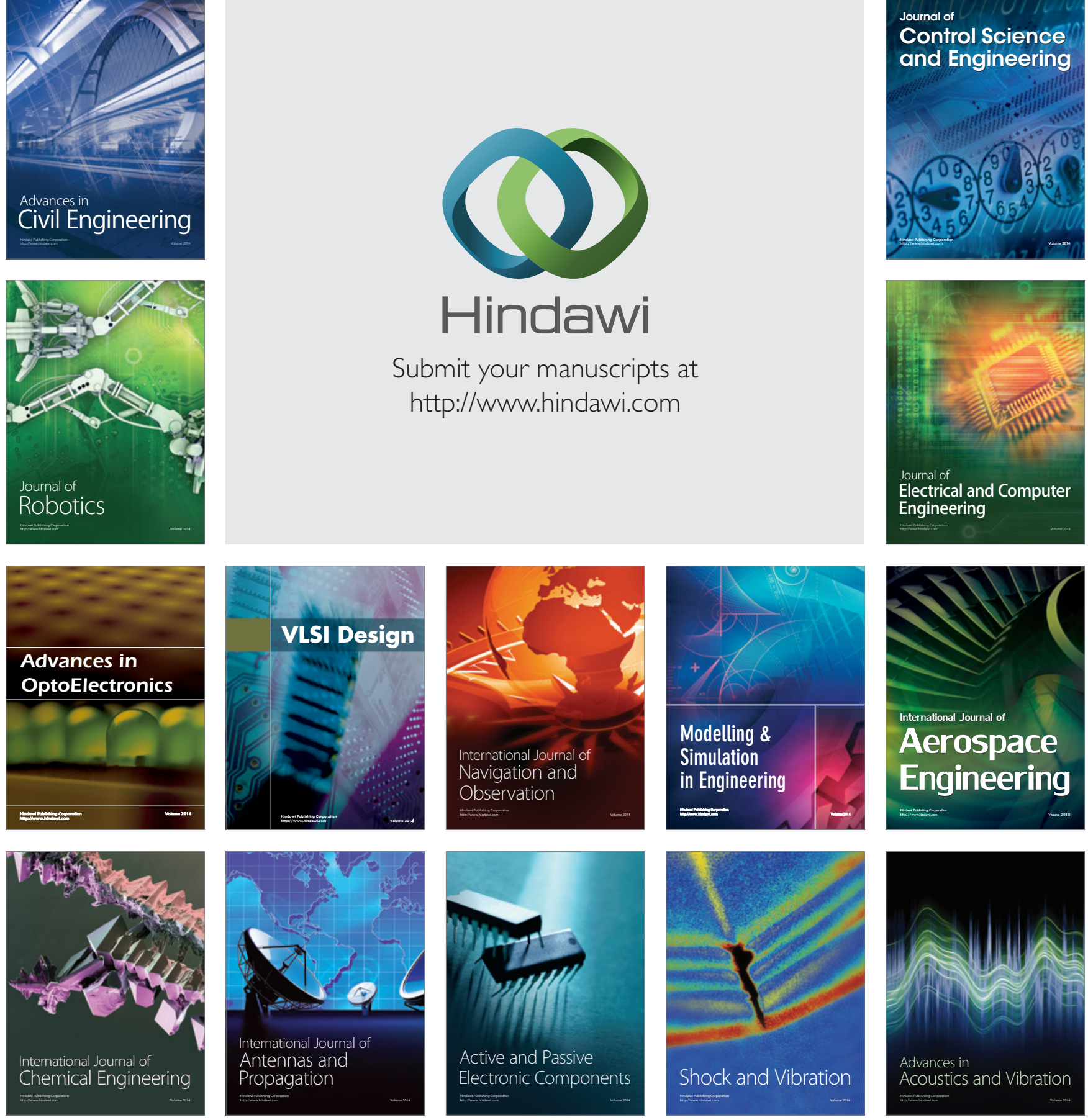